\title{
LabTecA - Laboratório Virtual de Química Analítica
}

\author{
Rogério A. Bordini, Joice Lee Otsuka, Delano Medeiros Beder, Thiago Morano da \\ Silva, Leonardo Tavares Oliveira, Ana Esther Rodrigues de Camargo, Catarine \\ Santana Ohnuma, Maria Teresa Mendes Ribeiro
}

\author{
Laboratório de Objetos de Aprendizagem - Universidade Federal de São Carlos \\ (UFSCar) - Caixa Postal 676 - CEP: 13565.905 - São Carlos/SP - Brasil \\ rogerio.bordinilsead.ufscar.br, \{joice, \\ delano\}@dc.ufscar.br, leonardotavares08@hotmail.com, \{thiago.morano159, \\ catarine.ohn, annaerodrigues\}@gmail.com, mtmrborg@cca.ufscar.br
}

Resumo. LabTecA é um jogo educacional que está sendo desenvolvido com o intuito de proporcionar vivências em um laboratório virtual de Química Analítica em 3D. Seu objetivo é promover experiências lúdicas de aprendizagem em um ambiente virtual em que o jogador é estimulado a explorar o uso de objetos próprios de um laboratório (equipamentos, vidrarias e reagentes) para realizar experimentos virtuais que são propostos ao longo do jogo. Este trabalho, portanto, apresenta as principais características de LabTecA, como sua narrativa, mecânica, estética, tecnologia, desafios e as dinâmicas de interação que permitem a vivência de uma experiência lúdica e educacional em um laboratório $3 D$.

\section{Cenário de uso}

O ensino de Química em muitas escolas brasileiras é prejudicado pela ausência de espaços apropriados para realização de atividades práticas relacionadas aos conteúdos vistos na teoria. A falta de laboratórios nas escolas pode implicar em uma formação incompleta ao aluno, visto que muitos fenômenos químicos, para serem efetivamente compreendidos, necessitam ser observados, analisados e manipulados por meio de experimentos, permitindo que o aluno realize associações entre esses aprendizados com o seu dia-a-dia. A existência de tais espaços fica acima das possibilidades reais da maioria dos estabelecimentos de educação do país; seja por falta de espaço físico adequado, ausência de instrumentação ou carência de materiais reagentes básicos. Na Educação a Distância, esse cenário também é agravado pelo fato da maior parte dos estudantes estarem distantes da universidade e, muitas vezes, também do polo de apoio presencial. A dificuldade de acesso aos laboratórios físicos frequentemente inviabilizam atividades práticas que requeiram o uso de equipamentos e materiais específicos.

Pesquisas sobre ambientes virtuais altamente interativos, como os laboratórios virtuais, indicam que estes recursos são apropriados e podem ser bastante efetivos para programas formais de aprendizagem (Aldrich, 2009; Squire et al. 2004). Alguns argumentos apresentados por Aldrich (2009, p. 5-6) para justificar a efetividade desses recursos são: (i) o emprego de elementos de jogos como ferramenta de aprendizagem, instigando e motivando o envolvimento dos aprendizes; (ii) a criação de contextos significativos e similares aos reais, onde o conhecimento construído poderá ser aplicado; (iii) a possibilidade de participação ativa do estudante, o que é essencial para uma aprendizagem efetiva; (iv) possibilidade de exploração dos recursos virtuais do laboratório. 
Este trabalho apresenta o jogo educacional de simulação LabTecA (Laboratório de Técnicas Analíticas) que vem sendo desenvolvido no Laboratório de Objetos de Aprendizagem (LOA) ${ }^{1}$ da Universidade Federal de São Carlos (UFSCar), tendo como objetivo proporcionar ao jogador vivências em um laboratório de Química Analítica. O projeto do jogo foi concebido a partir de uma demanda de uma professora de Química Analítica, Prof ${ }^{\mathrm{a}} \mathrm{Dr}^{\mathrm{a}}$ Maria Teresa Mendes Ribeiro Borges, que atua nos cursos de Engenharia Agronômica, Engenharia Ambiental, Biotecnologia e Tecnologia Sucroalcooleira oferecidos nesta universidade.

\section{Desenvolvimento}

O desenvolvimento do projeto tem sido realizado por estudantes de graduação de diferentes áreas (Química, Computação, Letras, Audiovisual e Música), os quais desempenham papéis de desenvolvedores, projetistas e ilustradores (tanto concentrados em modelagem 3D quanto ilustração). O projeto ainda tem contado com a participação e orientação de docentes das áreas de Química e Computação. O jogo está sendo desenvolvido colaborativamente por esta equipe interdisciplinar no próprio LOA, possibilitando um equilíbrio entre os elementos educacionais e os elementos básicos dos jogos (como mecânica, estética, narrativa e tecnologia).

Desde o início do projeto foram considerados os seguintes requisitos para o design do jogo com o intuito de se desenvolver um recurso educacional aberto capaz de contribuir para o aprendizado de Química Analítica de forma lúdica. Dessa forma, os requisitos macro do projeto são:

1. Possibilitar a simulação de experimentos de Química Analítica, contemplando um conjunto de equipamentos e procedimentos principais. Os estudantes devem poder experimentar virtualmente a manipulação de equipamentos e reagentes para a realização de experimentos, bem como analisar os comportamentos destes;

2. Oferecer uma experiência lúdica e interativa na qual o jogador possa se entreter ao explorar um ambiente virtual que simule o real contexto de um laboratório de química, podendo realizar diversos experimentos manipulando equipamentos, vidrarias e reagentes virtuais comuns a estes laboratórios;

3. Considerar os objetivos educacionais e os elementos de jogabilidade de forma equilibrada, de modo a oferecer uma experiência lúdica de aprendizagem significativa;

4. Favorecer o reuso, revisão, remixagem e redistribuição sem fins comerciais do jogo e de todos os seus componentes ${ }^{2}$, seguindo o movimento dos Recursos

\footnotetext{
1 Espaço interdisciplinar de estudos e pesquisas de novas tecnologias e metodologias para o desenvolvimento de objetos de aprendizagem interativos abertos, concentradas na utilização dos games. Website: http://www.loa.sead.ufscar.br

2 O jogo, bem como todos os seus componentes, ficarão disponíveis para a comunidade no Repositório Digital Livre Saber (livresaber.sead.ufscar.br), repositório digital de acesso livre da SEaD/UFSCar, onde
} 
Educacionais Abertos (D'antoni e Savage, 2009; Open Society Foundations \& Shuttleworth Foundation, 2007).

Para o desenvolvimento do protótipo foi utilizado o motor de jogo Unity ${ }^{3}$, que traz um conjunto de funcionalidades que facilitam e agilizam a criação de games em três dimensões, permitindo ainda uma maior produtividade quanto à programação (na linguagem C\#). O software utilizado para a produção das músicas foi Reason ${ }^{4}$, o qual possui um banco de samplers e efeitos que auxiliam na composição das trilhas. Quanto à modelagem $3 \mathrm{D}$ dos cenários e objetos, foi utilizado o software gratuito Blender ${ }^{5}$, o qual permite a criação de cenários e personagens de forma prática, além de permitir que seus modelos criados sejam importados e manipulados no Unity (Oliveira et al. 2012). As ilustrações das animações que aparecem entre as fases foram desenhadas por meio do Adobe Photoshop ${ }^{6}$ e os demais efeitos sonoros foram gravados e editados utilizando o software gratuito Audacity ${ }^{7}$.

Ademais, foi realizado um estudo para o design da interação do jogador com os objetos disponíveis no laboratório virtual (equipamentos, armários, vidrarias e reagentes) e o inventário do jogo (criado para possibilitar o armazenamento e o transporte de vidrarias, reagentes, compostos e resultados de análises).

A proposta de design foi elaborada tendo como objetivo proporcionar ao jogador/aprendiz uma experiência pela qual ele possa estar engajado com o gameplay, enquanto aprende os conceitos da disciplina de Química Analítica. Em um primeiro momento, a proposta de design teve como foco as interações com: (i) os armários, onde são armazenados reagentes e vidrarias; (ii) com as vidrarias e reagentes; (iii) com os equipamentos e (iv) com o inventário.

\section{Apresentação do Software}

LabTecA $^{8}$ é um adventure game, dotado de momentos de exploração, simulação e resolução de quebra-cabeças (puzzles). O jogo mantém o aluno focado nos experimentos e nos procedimentos corretos que deverá seguir com o intuito de cumprir as tarefas pré-determinadas em cada fase/ambiente.

\subsection{Narrativa}

A narrativa do jogo traz a história de Cris, uma funcionária recém contratada do LabTecA que é aprisionada por LIA (Labtech Inteligência Artificial), um sistema de segurança autônomo e inteligente utilizado para manutenção do laboratório, e que deseja dominar o mundo. A fim de concretizar seu plano maligno, LIA busca o condutor

está sendo organizado um acervo de objetos educacionais multimídia produzidos como recursos educacionais abertos.

${ }^{3}$ https://unity3d.com/pt

4 http://www.propellerheads.se/products/reason/

5 https://www.blender.org/

${ }^{6} \mathrm{http}: / / \mathrm{www}$.adobe.com/br/products/photoshop

${ }^{7}$ http://www.audacityteam.org/ 
VI Congresso Brasileiro de Informática na Educação (CBIE 2017)

Anais dos Workshops do VI Congresso Brasileiro de Informática na Educação (WCBIE 2017)

elétrico perfeito para conectar-se ao cabo que lhe concederá poder total, o qual poderá ser obtido por meio da ajuda de Cris. Diante disso, LIA solicita à pobre novata que execute uma lista de experimentos a fim de alcançar a criação do condutor elétrico.

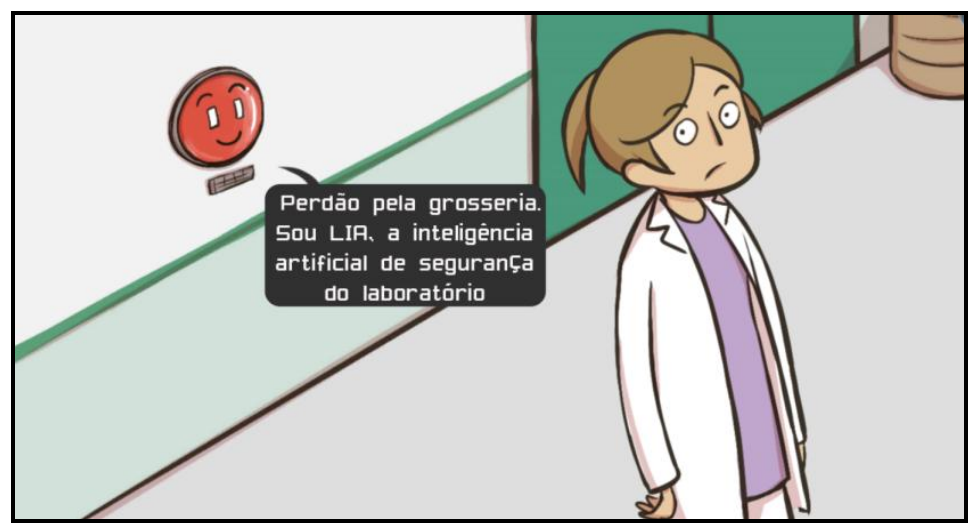

Figura 1. Personagens de LabTecA: LIA e Cris

\subsection{Estética}

Os cenários de LabTecA são predominantemente em três dimensões (3D) (Figura 2) e no estilo cartoon (Figura 1) nas cenas de animação que são apresentadas entre as fases do jogo, destacando pontos-chave da narrativa. O estilo 3D como forma de interação foi adotado por oferecer maior liberdade de exploração e por possibilitar que o jogador se aproximasse de um real contexto de laboratório de química.

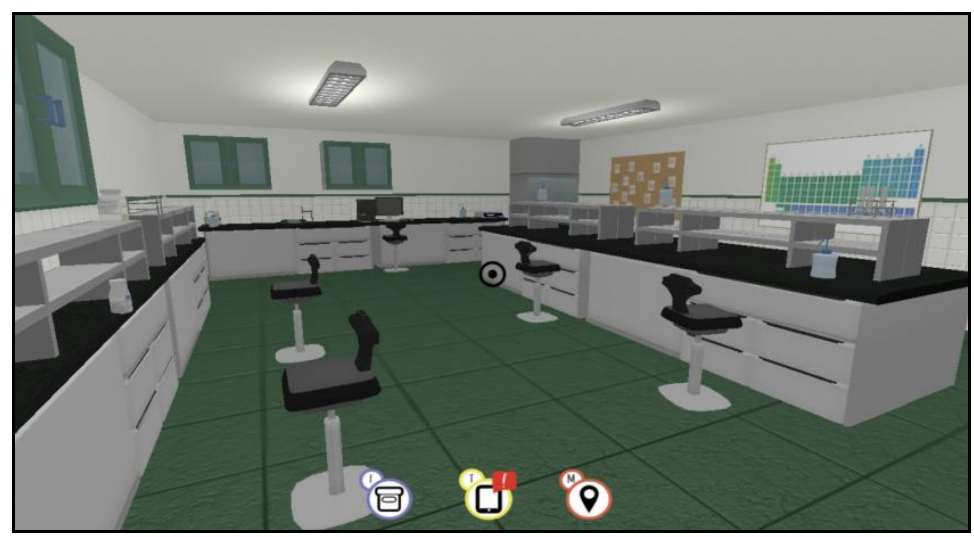

Figura 2. Cena do gameplay de LabTecA

Os gráficos em três dimensões também permitem a interação com os equipamentos modelados de acordo com seus formatos reais (Figura 3).

8 Link de acesso gratuito (CC) ao jogo: https://goo.gl/Bo3gZb. Acesso ao trailer do jogo: https://youtu.be/NtXzLDmuKMI 
VI Congresso Brasileiro de Informática na Educação (CBIE 2017)

Anais dos Workshops do VI Congresso Brasileiro de Informática na Educação (WCBIE 2017)

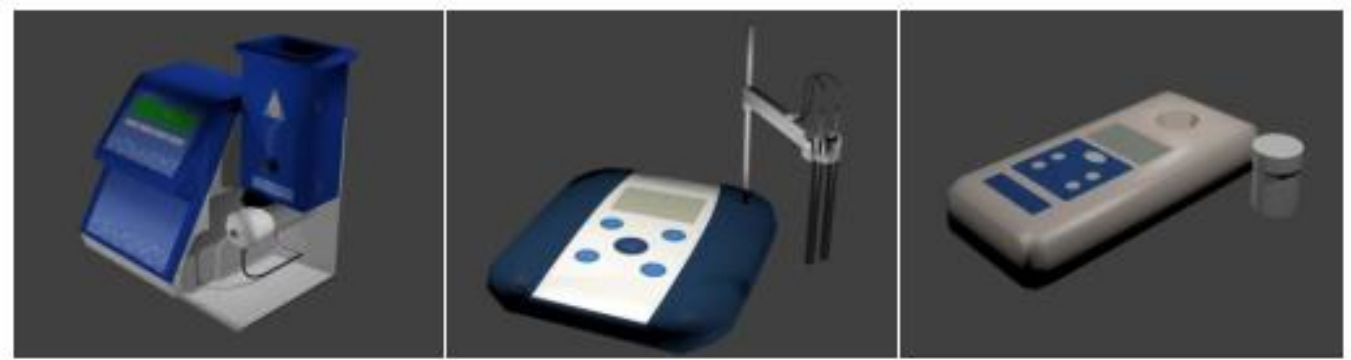

Figura 3. Equipamentos de laboratórios de química modelados para LabTecA

As músicas do jogo foram compostas de acordo com os variados contextos e cenários do jogo, para enfatizar momentos de ação ou como complemento sonoro durante a realização dos experimentos.

\subsection{Mecânica}

A câmera do jogo é em primeira pessoa e a movimentação da personagem ocorre por meio dos botões $\mathrm{W}, \mathrm{A}, \mathrm{S}, \mathrm{D}$ do teclado ao mesmo tempo em que o mouse é utilizado para rotacionar a câmera e interagir com os objetos dos cenários. A interação com equipamentos, bancadas e armários ocorre quando o jogador se aproxima e pressiona a tecla "E", que é referente ao comando de ação. A câmera então muda para a perspectiva ortogonal e uma interface é apresentada ao jogador com as possíveis interações disponíveis com o recurso em questão. Por exemplo, na interação com os armários (Figura 4), é apresentada uma lista contendo vidrarias e reagentes, permitindo que estes itens sejam adicionados ao inventário do jogador.

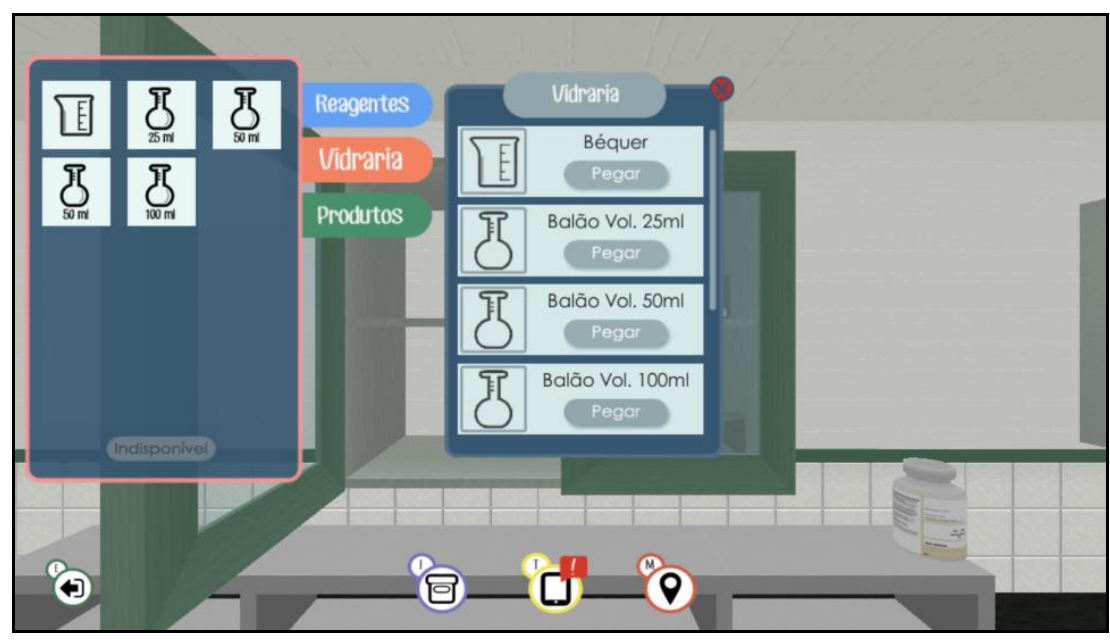

Figura 4. Exemplo de interação com o armário de vidrarias

O inventário (que pode ser acessado pressionando a tecla "I") possui três divisões para organização dos itens coletados ao longo do jogo: reagentes, vidrarias e produtos. Também há a presença de um mapa que pode ser acionado com a tecla "M" para auxiliar o jogador na exploração dos cenários. 
VI Congresso Brasileiro de Informática na Educação (CBIE 2017)

Anais dos Workshops do VI Congresso Brasileiro de Informática na Educação (WCBIE 2017)

A interação com os equipamentos ocorre de forma semelhante com a dos armários. Pressionando "E" no equipamento, são apresentadas as ações disponíveis. A Figura 5 apresenta a interface de interação com a balança de precisão, espátulas (para manusear reagentes sólidos), pipeta (para manusear e medir reagentes líquidos), e uma pisseta (para adicionar água destilada quando necessário).

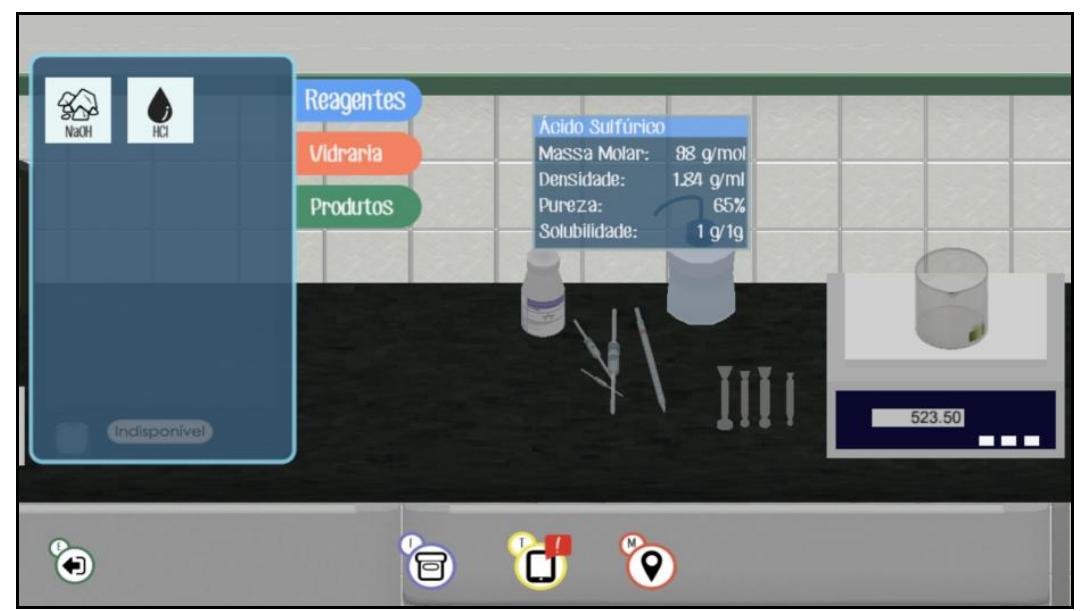

Figura 5. Exemplo de interação com os equipamentos e instrumentos do jogo

Para realizar os experimentos solicitados, é possível colocar as vidrarias na bancada, na balança e então, utilizando as ferramentas, adicionar reagentes, soluções, realizar a pesagem até que seja obtido o resultado necessário para a conclusão do experimento com sucesso.

Ao final de cada experimento, o jogador deve levar os resultados até LIA, que está localizada em uma das principais salas do laboratório (que pode ser facilmente encontrada acessando o mapa do jogo). Caso o experimento esteja correto, LIA enviará outra tarefa no tablet de Cris (que pode ser acessado pressionando a tecla "T"), caso contrário, a protagonista deverá refazer o processo até chegar no resultado esperado.

\subsection{Curva de Aprendizagem}

LabTecA foi projetado pensando em estudantes de ensino médio, técnico e de graduação, os quais já tiveram contato prévio com conteúdos baseados em Química Analítica. São propostos experimentos que o aluno/jogador deverá realizar ao longo do jogo, com uma curva de aprendizagem gradativa, de tarefas mais simples (como calibragem e limpeza de vidrarias) até as que exigem maior nível de conhecimento (como uso e leitura de espectrofotômetro, utilizado para medir a quantidade de luz absorvida por uma solução) ao final do jogo.

Por exemplo, nas primeiras fases o jogador deve preparar uma solução de $1 \mathrm{~mol} / \mathrm{L}$ de $\mathrm{NaOH}$, a qual exigirá aprendizagem de conceitos como diluição, ácido e base, bem como calibragem da balança de precisão. $\mathrm{O}$ aprendizado destes conceitos será essencial para a realização dos experimentos das fases seguintes, principalmente para o último experimento do jogo que exigirá a utilização da maioria dos conhecimentos químicos previamente fornecidos. Para além dos sete experimentos guiados pela vilã LIA, existem ainda os que a protagonista necessita realizar para escapar do laboratório sem 
compactuar com o plano maligno da vilã. Dessa forma, existem diferentes caminhos e experimentos que podem ser explorados pelo jogador, aumentando a motivação, imersão e o fator de replay.

Ademais, o jogador conta com o apoio de um tablet que pode ser acessado a qualquer momento, no qual é disponibilizado informações referentes aos experimentos, fórmulas e equipamentos do laboratório. Esse tablet também funciona como uma forma de rever informações e habilidades aprendidas, pois à medida que o jogador avança, torna-se necessário o uso dos conhecimentos previamente adquiridos nas fases anteriores para que se obtenha sucesso nas seguintes.

Equipamentos, vidrarias e salas serão liberados de acordo com o progresso do jogador.

\section{Considerações finais}

LabTecA surge como uma alternativa gratuita para auxiliar professores que queiram trazer em um recurso digital os conteúdos de Química Analítica que desejam trabalhar com os alunos de forma lúdica. Ademais, tendo em vista a carência de infraestrutura que a grande maioria das escolas brasileiras sofre, o referido jogo também pode ser considerado como um recurso digital eficaz tanto na realização de experimentos virtuais quanto na interação com equipamentos e vidrarias existentes em um real laboratório.

O protótipo apresentado neste trabalho foi validado pela professora especialista da área de Química Analítica, Prof ${ }^{\mathrm{a}} \mathrm{Dr}^{\mathrm{a}}$ Maria Teresa Mendes Ribeiro Borges, a qual interagiu com uma versão de PC em nosso laboratório e fez uma análise dos elementos educacionais do jogo. Foram identificadas novas opções de interação que deverão ser implementadas para possibilitar a realização de novos tipos de experimentos.

O jogo recentemente foi adaptado para ser inserido no escopo do projeto Recursos Educacionais Multiplataforma Abertos na Rede (REMAR) ${ }^{9}$, que visa prover uma plataforma de jogos educacionais abertos na qual é possível a criação de instâncias customizadas de jogos diretamente pelo professor, a partir de modelos de jogos abertos customizáveis. Na plataforma, os professores podem customizar um modelo do LabTecA $^{10}$ por meio do qual poderão inserir seus próprios experimentos a serem realizados pelos alunos.

Como trabalhos futuros, pretende-se refinar as interações com equipamentos, vidrarias, reagentes e inventário e realizar testes de usabilidade com especialistas e testes com o público-alvo, ou seja, estudantes de ensino médio, técnico e de graduação. Também se espera realizar avaliações usando instrumentos como o EGameFlow (Fu et al 2009), para a análise da adequação desse recurso como um jogo educacional, bem como para o direcionamento de futuros refinamentos.

\footnotetext{
9 Plataforma que tem como objetivo facilitar e ampliar a construção e o reuso de jogos educacionais abertos, por meio de um serviço online que oferece ferramentas que facilitam a construção e a customização de jogos. Atualmente a plataforma já abriga alguns jogos educacionais cujos conteúdos podem ser customizados e acessados por meio do endereço: http://remar.dc.ufscar.br/.

${ }_{10}$ Link de acesso a modelo customizável de LabTecA na plataforma REMAR: http://remar.dc.ufscar.br/resource/show/4. É necessário criar um cadastro gratuito para acessá-lo.
} 
VI Congresso Brasileiro de Informática na Educação (CBIE 2017)

Anais dos Workshops do VI Congresso Brasileiro de Informática na Educação (WCBIE 2017)

\section{Agradecimentos}

Os autores agradecem o apoio concedido pelo MEC/SESu (Edital ProEXT 2014), CAPES e CNPq; o suporte da Secretaria de Educação à Distância (SEaD), à PróReitoria de Extensão da UFSCar e a todos os professores, alunos e amigos que, direta ou indiretamente, vêm contribuindo com a realização deste projeto.

\section{Referências}

Aldrich, C. (2009) "Learning with games, simulations and virtual worlds: strategies for online instruction.” John Wiley \& Sons Inc.

D'antoni, S.; Savage, C. (Org.). (2015) "Open Educational Resources - Conversations in Cyberspace”. Paris: UNESCO, 2009. Disponível em: $<$ http://unesdoc.unesco.org/images/0018/001816/181682e.pdf >. Acesso em jul. 2017.

Fu, F. L.; Su, R. C.; Yu, S. C. (2009.) "EGameFlow: a scale to measure learners' enjoyment of eLearning games". In: Computers \& Education. Elsevier Educational Research Programme.

Oliveira, K. D.; Santos, W. L.; Souza, R. C.; Moura, R. O.; Silva, J. F. M. C.; Menezes, J. W. (2012) "Laboratório Virtual de Química: Blender 3D Auxiliando no ensino da Química”. In Xl Congresso Brasileiro de Educação em Engenharia. Belém-PA.

Open Society Foundations \& Shuttleworth Foundation. (2007) "Cape Town Open Education Declaration: Unlocking the promise of open educational resources". Cape Town, Africa, 2007. Disponível em: <http://www.capetowndeclaration.org/readthedeclaration>. Acesso em jul. 2017.

Squire, K. D. (2007) “Games, Learning and Society: Building a Field”. Educational Technology. p. 52-53. 